\title{
DESVOZEAMENTO DAS VOGAIS MÉDIAS PRETÔNICAS NO PORTUGUÊS DA AMAZÔNIA PARAENSE: A QUARTA VARIANTE ${ }^{1}$ \\ UNSTRESSED MID VOWEL DEVOICING IN BRAZILIAN \\ PORTUGUESE SPOKEN IN AMAZON: THE FOURTH VARIANT
}

Regina Celia Fernandes Cruz ${ }^{2}$

Resumo: O presente artigo, vinculado ao PROBRAVO, fornece os resultados preliminares alcançados com a investigação acústica das vogais médias pretônicas da variedade do português falada na capital paraense, Belém (BE0). O corpus original tinha amostras de fala de 18 informantes nativos de Belém (PA), que produziram 74 vocábulos contendo as vogais-alvo pretônicas, gravados em testes por indução de imagens e por leitura em voz alta. O objetivo inicial do estudo visava a caracterização acústica de três variantes das vogais médias pretônicas identificadas na literatura existente para o português brasileiro: alteamento, manutenção e abaixamento. Ao se proceder à análise acústica dos dados de $B E 0$, constatou-se a existência de uma quarta variante no nível acústico, o desvozeamento da vogal média pretônica. Analisaram-se aqui apenas 89 casos de desvozeamento das vogais médias pretônicas identificados em BE0, e adianta-se que há casos de apagamento tanto de vogais posteriores quanto de anteriores.

Palavras-chave: Vogais Médias Pretônicas, Análise Acústica, Desvozeamento, Português Brasileiro.

\begin{abstract}
This work is linked to PROBRAVO team. Actually, we present only one of all the results achieved on the unstressed vowels of the linguistic variety spoken in Belem (BE0) that have been investigated acoustically. The whole corpus is formed by a sample of speech of 18 native speakers who were recorded in two different situations: induced test and speech reading. They produced 74 words which contain the target unstressed vowels. The first aim of this study was to describe acoustically three variants of unstressed mid vowels identified in the state of art in Brazilian Portuguese, which are: high, mid and low. During the acoustic analysis of data of BE0, we noticed a fourth variant at the acoustic level, the devoicing of unstressed mid vowels. For this reason, we analyze here only those 89 cases of devoicing of target vowels identified in the

1 Este trabalho recebeu financiamento da Fulbright Fondation e da Coordenação de Aperfeiçoamento de Pessoal de Nível Superior (CAPES) no período de 2010-2011 (Processo BEX 1754/10-6), quando foi executado no Departamento de Linguística da New York University, sob a supervisão de Gregory Guy.

2 Professora da Universidade Federal do Pará, pesquisadora do CNPq.
\end{abstract}


corpus. We noticed cases of devoicing in both front and back mid vowels. Keywords: Unstressed mid vowels, Acoustic analysis, Devoicing, Brazilian Portuguese.

\section{Introdução}

O presente trabalho apresenta os resultados preliminares obtidos com o estudo acústico do sistema vocálico do português falado na Amazônia paraense. Trata-se de um estudo vinculado ao PROBRAVO ${ }^{3}$ e tem como objetivo principal analisar acusticamente o sistema vocálico átono do Português Brasileiro $(\mathrm{PB})$ falado no estado do Pará. O projeto já conta com corpora de quatro variedades locais: Belém - BE0 - (CRUZ, 2011; CRUZ; COSTA; SILVA, 2012); Cametá - BE4 -; Mocajuba - BE5 - e Bragança BE3 - (CAVALCANTE, em andamento).

Apesar de o objetivo inicial do estudo acústico empreendido sobre o sistema vocálico do português falado na Amazônia paraense compreender a descrição das três variantes das vogais médias pretônicas - /e/ e /o/ tradicionalmente identificadas na literatura sobre o assunto, a saber: alta ([i] ${ }^{4}$ e $\left.[\mathrm{u}]\right)$, média ([e] e [o]) e baixa ([E] e [O]), durante o trabalho de segmentação, tratamento e análise acústica dos dados da variante linguística de Belém (BE0), detectou-se a ocorrência de uma quarta variante no nível acústico: o desvozeamento de vogais médias pretônicas.

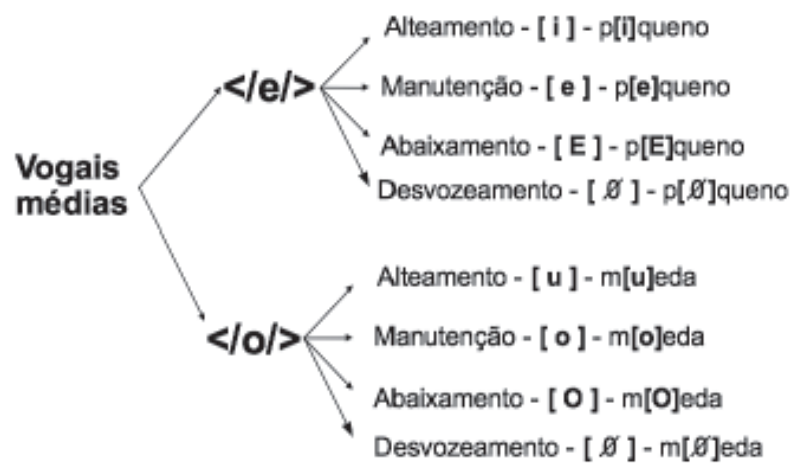

Fig. 1 - Variantes das vogais médias pretônicas, objeto de estudo do projeto Norte Vogais. Fonte: Adaptado de Cruz (2012b, p. 952)

3 Trata-se do diretório de pesquisa nacional Descrição Sócio-Histórica das Vogais do Português (do Brasil), coordenado pelo Dr. Marco Antônio de Oliveira (PUC-MG) e Dr. Seung-Hwa Lee (UFMG) e do qual fazem parte 19 outras instituições nacionais, além da UFPA e da própria UFMG que sedia o projeto. Para maiores detalhes, consultar $<\mathrm{http}$ //www.geocities.com/probravo/>.

4 Utilizaram-se aqui os símbolos do alfabeto SAMPA para a transcrição fonética.

5 Optou-se por transcrever o desvozeamento com o símbolo [ $\square]$. 
É justamente sobre essa quarta variante que tratará o presente trabalho (de modo mais minucioso na Seção 5). Informações detalhadas sobre o estudo acústico das vogais médias pretônicas empreendido pela equipe da UFPA, vinculada ao PROBRAVO, são fornecidas nas seções 3 e 4. Foi necessário, apresentar também, de forma geral, a atuação da equipe da UFPA no PROBRAVO, o que é feito na seção seguinte (Seção 2). Antes da conclusão propriamente dita (Seção 7), encerrou-se o presente trabalho, ressaltando a importância de se trabalhar com o tipo de corpus adotado e apresentando as ações futuras de exploração dos casos de desvozeamento identificados no português falado na Amazônia paraense tratados aqui (Seção 6).

\section{Projeto Norte Vogais}

Na região Norte, os estudos sobre as vogais átonas foram impulsionados com a entrada da equipe do projeto Norte Vogais, no Diretório Nacional de Pesquisa do CNPq PROBRAVO. Antes do trabalho da equipe desse projeto, tem-se o registro de raros estudos sobre o tema na variedade do português falado na Amazônia paraense (NINA, 1991; FREITAS, 2001). De maneira geral, a equipe da UFPA, vinculada ao PROBRAVO, pretende caracterizar o sistema vocálico átono e suas variantes, com base em amostra estratificada e em termos variacionistas, assim como analisar qualitativamente e explicar o processo de variação das vogais médias pretônicas no português falado no norte do Brasil condicionado por fatores internos.

O projeto Norte Vogais, inicialmente, formou corpora com amostras de fala das variedades linguísticas do português da Amazônia paraense, situadas na zona do Português Regional Paraense na classificação dialetal de Cassique (2006 apud CRUZ, 2012a).

Cassique (2006), tomando como base as considerações de Silva Neto (1957), apresenta uma nova divisão dialetal do Pará (cf. figura 2) que está sendo considerada pelos pesquisadores da UFPA ligados ao projeto PROBRAVO e, consequentemente, está na base da escolha das localidades-alvo do presente projeto. A divisão dialetal do Pará estabelecida pelo autor citado considera as várias fases migratórias ocorridas no estado e que foram responsáveis pelas alterações da configuração original da situação sociolinguística da região. A primeira fase corres- 
ponde à chegada dos açorianos ao Pará ainda no século XVII, quando a língua portuguesa não conseguia sua implantação definitiva, uma vez que se atesta a situação de língua Franca com o domínio de uma variante do tupinambá, a Língua Geral Amazônica (doravante LGA) (CALDAS; FERNANDES; CRUZ, 2005).

Segundo Rodrigues (1996), a primeira importante leva de falantes nativos do português chegou à Amazônia apenas no primeiro Ciclo da Borracha no século XVIII: são os nordestinos que migraram para a Amazônia, seduzidos pelo poder econômico da borracha. Até o final do século XIX, o português falado em todo o Pará foi o resultado do contato direto com a LGA, este português resiste ainda hoje na zona 1, da figura 2 .

As cidades paraenses fundadas na época do Brasil Colonial, como Belém, Cametá ou Mocajuba, por exemplo, mantêm uma variedade linguística com forte influência da LGA. Exceção feita à região Bragantina (cf. zona 2 da figura 2) que, apesar de englobar a cidade de Bragança (também uma cidade do Pará com fundação histórica), possui uma variedade linguística que sofre forte influência do falar nordestino por causa de sua proximidade geográfica com o Maranhão e, portanto, registra um contato intenso com a variedade linguística do oeste maranhense.

Nos anos 1970, o Português Regional Paraense sofreu mais uma alteração, quando governos militares incentivaram a migração do Sul do Brasil para a Amazônia, com a abertura da Transamazônica. A migração ocorrida se concentrou no sul e sudeste do Pará, alterando radicalmente o português falado nessas regiões e criando uma outra norma distinta (zona 3 da figura 2) do Português Regional Paraense, cujo reduto é, de acordo com Cassique (2006 apud CRUZ, 2012a), (a) o médio Amazonas paraense; (b) a região do Salgado; (c) a Ilha de Marajó; (d) o nordeste paraense e (e) a capital paraense, Belém. Portanto, na figura 2, abaixo, visualiza-se a região do Português Regional Paraense (1), do dialeto bragantino (2) e da zona de contato interdialetal (3). O Português Regional Paraense é também aquele considerado por Silva Neto (1957) como sendo o de canua cheia de cucus de pupa a prua, por conta de sua principal marca dialetal, o alteamento das vogais posteriores em posição de sílaba tônica (cf. RODRIGUES, 2005). As localidades investigadas e selecionadas para constituírem a área geográfica de atuação do projeto Norte Vogais pertencem ao Português Regional Paraense (cf. Zona 1 da figura 2), Bragança é a única localidade pertencente ao dialeto bragantino (cf. Zona 2 da figura 2). 


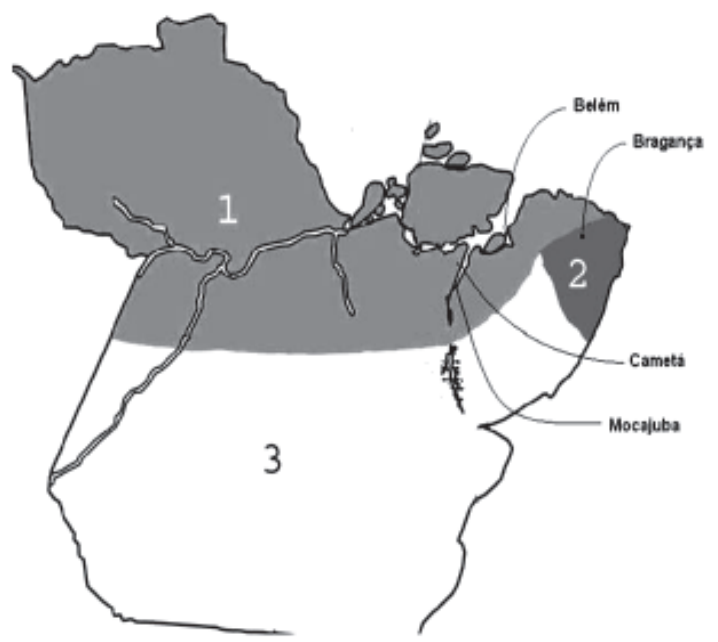

Fig. 2 - Localidades-alvo do Projeto Norte Vogais cuja variedade está sendo investigada acusticamente. Fonte: Adaptado de Cruz (2012a, p. 207)

O projeto Norte Vogais, estuda o processo de variação das vogais átonas no português falado em três ${ }^{6}$ localidades do estado do Pará, presentes na figura 2: i) em Cametá (RODRIGUES; ARAÚJO, 2007; RODRIGUES; REIS, 2012; COSTA, 2010); ii) em Mocajuba (CAMPOS, 2008); iii) e em Belém (SOUSA, 2010; CRUZ et alli, 2008).

No projeto, observou-se uma preferência dos dialetos paraenses à não aplicação da regra de alteamento das vogais médias pretônicas, como pode ser verificado na figura 3 . Os estudos também confirmam que, quando ocorre o alteamento das vogais médias pretônicas nos dialetos paraenses, o mesmo se dá motivado por uma clara harmonização vocálica, principalmente, condicionada pela vogal da sílaba tônica e pela sílaba imediata.

Este processo de harmonia vocálica atestado nos dialetos paraenses contempla as hipóteses de Câmara Jr. (1969) e de Silva Neto (1957) ao mesmo tempo. De acordo com Câmara Jr. (1969), o alçamento da pretônica é determinado pela altura da vogal da tônica, um dos fatores mais favorecedores do alteamento das vogais médias pretônicas nos dialetos paraenses. Silva Neto (1957), por sua vez, afirma ser o alçamento ainda mais favorecido por sílaba com vogal alta contígua e imediata à sílaba da vogal pretônica, outro fator altamente favorecedor do alteamento das médias pretônicas nos dialetos paraenses.

Outro resultado relevante compreende a inexpressiva ocorrência de vogais médias baixas nas posições átonas. Tais resultados contrariam, de

6 Não foram considerados os resultados da variedade linguística bragantina, porque a descrição sociolinguística de Bragança foi realizada por Freitas (2001), e não se trata de um estudo vinculado ao PROBRAVO. 
um lado, a divisão dialetal de Antenor Nascente que caracteriza os dialetos do norte do Brasil como apresentando uma tendência à realização das vogais médias abertas nas posições átonas, em oposição aos dialetos do sul do Brasil que preferiam as vogais médias fechadas. Por outro lado, os resultados reforçam a hipótese de Silva Neto (1957) de que o Pará compreenderia uma ilha dialetal na classificação de Antenor Nascentes entre os dialetos do norte do Brasil?

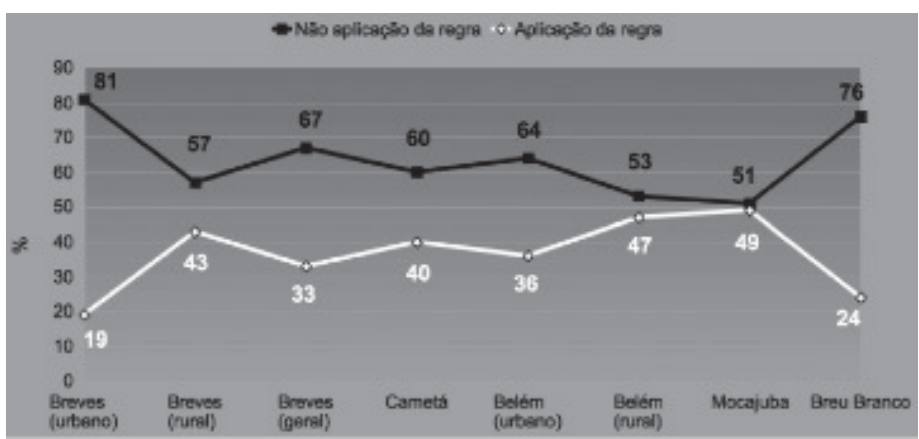

Fig. 3 - Tendência à regra de não alteamento das vogais médias pretônicas no Português da Amazônia paraense, de acordo com os resultados dos trabalhos realizados pela equipe do Projeto Norte Vogais da UFPA. Fonte: Cruz (2012b, p. 958)

O projeto de análise acústica do sistema vocálico do português falado na Amazônia paraense nasceu, portanto, da necessidade de refinamento das descrições sociolinguísticas empreendidas pela equipe do projeto vinculada ao PROBRAVO. Portanto, atualmente, a equipe do Norte Vogais está procedendo a uma análise qualitativa e acústica dos corpora de Belém, Cametá, Mocajuba e Bragança de modo a precisar se o alteamento das médias pretônicas nessas variedades, quando se dá, é de fato motivado por harmonia vocálica.

\section{Procedimentos Metodológicos Adotados na Análise Acústica das Vogais ${ }^{8}$}

O projeto Norte Vogais tem, também, como objetivo caracterizar acusticamente as vogais orais tônicas e átonas das variedades estudadas da

7 Silva (1989) menciona nos seus resultados, uma predominância das vogais baixas no seu corpus formado não somente com amostras de fala do dialeto-alvo - o de Salvador -, que também fora confrontado com amostras de fala de 50 pontos do território baiano e de uma localidade do estado de Sergipe emprestadas, respectivamente, do Atlas Prévio dos Falares Baiano e de Mota (1979).

8 A metodologia aqui descrita foi empreendida por Cruz (2011), em seu estágio pós-doutoral no Departamento de Linguística da New York University, no período de setembro de 2010 a março de 2011, quando obteve uma bolsa Fulbright/Capes pelo Edital DRI/CGCI n. 027/2009 (Processo BEX 1754/10-6), na condição de Pesquisadora-Visitante. 
Amazônia paraense. Para o estabelecimento das características acústicas, estão sendo considerados os parâmetros físicos de F1, F2, F0 intrínseca e de duração. Pretende-se, igualmente, proceder a uma comparação dos sistemas vocálicos tônicos do português da Amazônia paraense e do PB (MORAES; CALLOU; LEITE, 2002; CAGLIARI, 1977). No que diz respeito à F0 intrínseca das vogais, pretende-se igualmente verificar como se caracterizam as vogais da Amazônia paraense com relação aos dados fornecidos por Oliveira (1999) para o PB.

Inicialmente, quatro variedades da Amazônia paraense (Belém, Cametá $^{9}$, Mocajuba $^{10}$ e Bragança ${ }^{11}$ ) estão sendo investigadas com o objetivo principal de analisar acusticamente o seu sistema vocálico tônico e átono. Para tal, formaram-se corpora com a mesma estratificação social adotada para as descrições sociolinguísticas: Faixa Etária, Nível de Escolaridade ${ }^{12}$, Sexo e Dialeto e até, o presente momento, o projeto dispõe de um material gravado para análise acústica com 108 informantes ${ }^{13}$.

Cada informante participou de dois protocolos diferentes de coleta de dados: a) um teste de projeção de imagens ${ }^{14} \mathrm{e}$ b) a leitura em voz alta de um texto sobre futebol. Para a composição do instrumento de coleta de dados, foram utilizados 73 vocábulos contendo os mesmos contextos selecionados pelo programa Varbrul como favorecedores para explicar o fenômeno de variação das vogais-alvo em suas descrições variacionistas prévias (RODRIGUES; ARAÚJO, 2007; DIAS; CASSIQUE; CRUZ, 2007; CAMPOS, 2008; CRUZ et alli, 2008; CASSIQUE et alli, 2009; SOUSA, 2010).

Dentre estes 73 vocábulos foi utilizado no texto um instrumento de coleta para a fala lida de 51 vocábulos, os quais estão listados na figura 4. Aos 108 sujeitos foi solicitado, primeiramente, que dissessem o que viam logo depois que cada imagem era projetada. Projetou-se a sequência das 69 imagens duas vezes, no mínimo, a cada participante da pesquisa. Os verdadeiros objetivos da pesquisa não foram revelados, de imediato, a nenhum deles; apenas tomaram conhecimento dos objetivos, quando da

9 Sob responsabilidade de Raquel Costa (UFPA/UFC).

10 Sob responsabilidade de Socorro Campos (UFPA/UFC).

11 Sob responsabilidade de Carlos Nedson (UFPA).

12 Como o protocolo experimental prevê a etapa de leitura de texto, os sujeitos analfabetos foram excluídos naturalmente.

13 Foram 18 nativos da capital paraense, 36 da cidade de Cametá (18 da zona urbana e 18 da zona rural), 36 da cidade de Mocajuba (18 da zona urbana e 18 da zona rural) e 18 da cidade de Bragança.

14 A montagem desse teste foi feita com base em Ribeiro (2007) e Costa (2010) que empregaram este mesmo tipo de instrumento de coleta de dados ao estudar as médias postônicas não finais. Vale ressaltar que os dados do teste de imagens correspondem apenas a uma faixa etária (de 15 a 25 anos). 
assinatura do Termo de Consentimento Livre e Esclarecido (TCLE) do projeto. Uma vez aplicado o teste de imagens, passou-se, em seguida, à leitura do texto. Cada informante teve um tempo de 10 minutos de familiarização com o assunto do texto - futebol - de modo que a leitura fosse a mais natural possível.

\begin{tabular}{|c|c|c|c|c|c|}
\hline \multicolumn{3}{|c|}{$\mid \mathrm{e} /$} & \multicolumn{3}{|c|}{101} \\
\hline apos/e/ntado & b/e/bida & cab/e/ludo & ap/o/sentado & $\mathrm{b} / \mathrm{o} /$ necas & $\mathrm{b} / \mathrm{o} / \mathrm{rracha}$ \\
\hline c/e/rvejas & c/e/rtificado & /e/scravo & c/o/sturar & c/o/mer & c/o/rujas \\
\hline /e/mpregos & /e/stante & f/e/chado & c/o/mandante & c/o/legios & c/o/zinha \\
\hline fut/e/bol & $\mathrm{m} / \mathrm{e} / \mathrm{nino}$ & mosqu/e/teiros & $\mathrm{d} / \mathrm{o} /$ mingo & $\mathrm{h} / \mathrm{o} /$ spitais & $\mathrm{m} / \mathrm{o} / \mathrm{eda}$ \\
\hline $\mathrm{p} / \mathrm{e} / \mathrm{queno}$ & $\mathrm{p} / \mathrm{e} / \mathrm{scador}$ & $\mathrm{pr} / \mathrm{e} /$ ciso & $\mathrm{m} / \mathrm{o} /$ rador & $\mathrm{m} / \mathrm{o} /$ squeteiros & nam/o/rados \\
\hline $\mathrm{pr} / \mathrm{e} /$ sidente & $\mathrm{pr} / \mathrm{e} / \mathrm{sente}$ & $\mathrm{pr} / \mathrm{e} / \mathrm{sidio}$ & p/o/licia & $\mathrm{pr} / \mathrm{o} /$ fundo & $\mathrm{pr} / 0 /$ cissao \\
\hline qu/e/rida & r/e/medios & r/e/polhos & r/o/cambole & $\mathrm{R} / \mathrm{o} /$ ndonia & t/o/alha \\
\hline s/e/gundo & s/e/tenta & s/e/nhoras & t/o/mate & s/o/brinho & \\
\hline t/e/soura & t/eatro & v/e/ado & & & \\
\hline v/e/rgonha & & & & & \\
\hline
\end{tabular}

Fig. 4 - Lista dos 51 vocábulos contendo as vogais-alvo médias presentes no texto utilizado para a coleta de dados de fala lida

Para formar o corpus do teste de imagens, utilizaram-se quase todos os 51 vocábulos acima, retirando-se apenas quatro ${ }^{15}$ : 'querida', 'sobrinho', 'senhoras' e 'escravo'; e acrescentando-se 22 novos vocábulos. Neste momento, utilizou-se, prioritariamente, os vocábulos indicados por Bisol (1981) contendo vogais pretônicas em contexto de alta variabilidade como 'formiga,' 'fogueira,' 'bonita,' 'menino'. A figura 5 contém todos os vocábulos presentes no teste de imagens. Portanto, de cada informante foram obtidos dois tipos de dados: aqueles produzidos por indução com a projeção das imagens e os dados de fala lida. Apenas os dados da variedade de Belém (PA) estão com suas análises mais avançadas - sejam dos dados obtidos com o teste de imagens, sejam dos dados de fala lida - (CRUZ; COSTA; SILVA, 2012).

Concluídas todas as etapas anteriores de coleta de dados, procedeu-se ao tratamento dos dados que compreende seis etapas bem estabelecidas: a) segmentação do sinal de áudio de cada informante no programa PRAAT: enunciado, indicação da palavra-alvo, duração da palavra, sílaba,

15 Retiraram-se os vocábulos que apresentariam dificuldades para serem utilizados em forma de imagens. 
transcrição fonológica da vogal, transcrição fonética da vogal ${ }^{16}$; b) extração dos vocábulos-alvo das gravações originais com o programa $P R A A T$, seguido de codificação dos mesmos ${ }^{17}$; c) levantamento das ocorrências dos vocábulos-alvo por informante e por tipo de coleta de dados; d) identificação das variantes ocorridas por vocábulo, considerando os dados de cada informante; e) organização dos dados obtidos em uma planilha Excel para o registro das medidas acústicas tomadas de cada vogal-alvo.

\begin{tabular}{|c|c|c|c|c|c|}
\hline \multicolumn{3}{|c|}{ /e/ } & \multicolumn{3}{|c|}{$10 /$} \\
\hline apos/e/ntado & b/e/bidas & cab/e/ludo & ap/o/sentado & $\mathrm{b} / \mathrm{o} /$ necas & $\mathrm{b} / 0 /$ nita \\
\hline c/e/rvejas & c/e/rtificado & $\mathrm{d} / \mathrm{e} / \mathrm{z} / \mathrm{e} / \mathrm{sseis}$ & b/o/rracha & c/o/brador & c/o/madre \\
\hline /e/mpregos & /e/scola & /e/stante & c/o/sturar & c/o/mer & c/o/mandante \\
\hline f/e/chado & fut/e/bol & f/e/liz & c/o/legios & c/o/zinha & c/o/rujas \\
\hline $\mathrm{m} / \mathrm{e} /$ nino & mosqu/e/teiros & p/e/scador & $\mathrm{d} / \mathrm{o} /$ mingo & f/o/gueira & f/o/guete \\
\hline $\mathrm{p} / \mathrm{e} / \mathrm{pino}$ & $\mathrm{p} / \mathrm{e} / \mathrm{rfume}$ & $\mathrm{pr} / \mathrm{e} / \mathrm{sente}$ & f/o/lia & f/o/rmiga & f/o/rmigueiro \\
\hline p/e/queno & $\mathrm{p} / \mathrm{e} /$ rigo & $\mathrm{pr} / \mathrm{e} / \mathrm{ciso}$ & g/o/rdura & g/o/vernador & $\mathrm{h} / \mathrm{o} /$ spitais \\
\hline $\mathrm{pr} / \mathrm{e} /$ guiça & $\mathrm{pr} / \mathrm{e} / \mathrm{sidio}$ & $\mathrm{pr} / \mathrm{e} /$ sidente & /1/o/teria & $\mathrm{m} / \mathrm{o} / \mathrm{eda}$ & $\mathrm{m} / \mathrm{o} / \mathrm{squeteiros}$ \\
\hline qu/e/brado & r/e/medios & r/e/polhos & $\mathrm{m} / \mathrm{o} /$ rador & nam/o/rados & $\mathrm{p} / \mathrm{o} / \mathrm{licia}$ \\
\hline s/e/gundo & s/e/tenta & s/e/rviço & $\mathrm{pr} / \mathrm{o} /$ fessora & $\mathrm{pr} / \mathrm{o} /$ fundo & $\mathrm{pr} / \mathrm{o} /$ cissao \\
\hline t/eatro & t/e/soura & v/e/ado & R/o/ndonia & r/o/cambole & s/o/rriso \\
\hline v/e/rgonha & & & t/o/mate & t/o/alha & \\
\hline
\end{tabular}

Fig. 5 - Lista dos 69 vocábulos representados por figuras utilizadas para o teste de imagens

Primeiramente, os sinais de áudio originais de cada informante são segmentados em 6 níveis no programa PRAAT. Em seguida, procedeu-se à extração dos vocábulos-alvo e seu isolamento em um arquivo individual, preservando seu sinal sonoro e sua transcrição no TextGrid ${ }^{18}$. Para tal, utiliza-se um recurso do próprio PRAAT (Extract Selected Sound e Extract Selected TextGrid). Passou-se então à codificação ${ }^{19}$ do vocábulo contendo

16 Para a transcrição fonética, está sendo adotado o alfabeto SAMPA. Ver:<www.phon.ucl.ac.uk/ home/sampa/>.

17 Os informantes recebem um código que identifica dialeto, sexo, escolaridade e faixa etária de cada um. Adaptou-se para o presente projeto um código muito semelhante ao código fornecido pelo projeto AMPER-POR: <http://pfonetica.web.ua.pt/AMPER-POR.htm>. Uma vez esse código montado, escreve-se a palavra-alvo seguida de seu número de ocorrência no corpus gravado.

18 Arquivo fornecido pelo PRAAT contendo a segmentação do sinal de áudio.

19 A variedade de Cametá é identificada pelo código BE5; de Mocajuba pelo código BE4 e de Belém pelo código BE0. Para a identificação do sexo utilizam-se as letras maiúsculas M (sexo masculino) e F (sexo feminino). No caso da faixa etária, o código utilizado comprende os algarismos 1 (15 a 25 anos), 2 (26 a 45 anos) e 3 (acima de 46 anos). Por último, o nível de escolaridade é identificado pelas letras maiúsculas A (Nível Fundamental), B (Nível Médio) e C 
as informações sociais do locutor, do tipo de situação de fala gravado - teste de imagens ou fala lida - e o próprio vocábulo em si. Este mesmo código foi utilizado para nomear o novo arquivo criado. De posse dos vocábulos em arquivos isolados, procedeu-se ao levantamento e registro das variantes de vogais médias pretônicas identificadas no corpus, por locutor, em um formulário-controle padrão. Foram então tomadas medidas de F1, F2, F0 e da duração das vogais-alvo médias na posição pretônica na parte central das vogais. A tomada de medidas acústicas foi feita também com o auxílio do programa PRAAT. São também realizadas medidas das vogais tônicas destes mesmos 73 vocábulos com o objetivo de apresentação de um espaço vocálico de referência. $\mathrm{O}$ tratamento estatístico inicial compreendeu tomadas de Média, de Desvio Padrão e um teste T dos valores obtidos.

\section{Caracterização Acústica das Vogais do Norte do Brasil: Análise Preliminar}

Em geral, as análises acústicas têm confirmado os resultados das descrições sociolinguísticas de que a manutenção das médias é a variante de maior ocorrência no português falado na Amazônia paraense. Entretanto, tem destoado com relação ao ranqueamento da segunda e terceira variantes. No corpus controlado para as análises acústicas, as variantes baixas têm ocorrência bem maior do que o alteamento das médias pretônicas. Com relação ao nível de escolaridade, os falantes de baixa escolaridade possuem comportamento linguístico distinto dos falantes de alta escolaridade (níveis Médio e Superior), independentemente do sexo.

Calcularam-se apenas as médias dos valores em Hz de F1 e F2, para uma análise acústica preliminar com os dados de fala lida. Apesar de ainda se estar procedendo a um tratamento estatístico descritivo e nenhum tipo de normalização ter sido realizado com os dados, os resultados são relevantes, pois mostram que, no caso das vogais anteriores, tanto na fala masculina quanto na fala feminina a variante alta ocupa quase o mesmo espaço acústico que a variante média fechada e ambas se apresentam bem distantes da variante baixa. Por outro lado, as vogais posteriores são bem discriminadas acusticamente, tanto na fala masculina quanto feminina, como se pode constatar nas figuras 6 e 7 .

(Nível Superior). Para identificação do tipo de protocolo de coleta de dados realizado, utiliza-se a letra X para identificação dos dados obtidos com o teste de projeção de imagens e a letra $\mathrm{Y}$ para os dados de fala lida. Uma vez esse código montado, escreve-se a palavra-alvo seguida de seu número de ocorrência no corpus gravado.

Organon, Porto Alegre, v. 28, n. 54, p. 115-136, jan./jun. 2013. 


\begin{tabular}{|c|c|c|c|c|c|c|c|c|c|c|}
\hline \multirow{2}{*}{ Variante } & \multirow{2}{*}{$\begin{array}{l}\text { No de } \\
\text { ocorrências }\end{array}$} & \multicolumn{4}{|c|}{ Média } & \multicolumn{4}{c|}{ Desvio Padrão } \\
\cline { 2 - 12 } & Masc. & Fem. & Masc. & Fem. & Masc. & Fem. & Masc. & Fem. & Masc. & Fem. \\
\hline $\mathrm{i}$ & 16 & 29 & 369 & 405 & 1994 & 2115 & 39 & 62 & 183 & 342 \\
\hline $\mathrm{e}$ & 138 & 51 & 396 & 473 & 1916 & 2055 & 36 & 76 & 156 & 222 \\
\hline $\mathrm{E}$ & 44 & 137 & 501 & 610 & 1768 & 2239 & 51 & 48 & 137 & 234 \\
\hline 0 & 60 & 59 & 563 & 645 & 1114 & 1149 & 72 & 81 & 401 & 242 \\
\hline 0 & 76 & 78 & 447 & 490 & 1154 & 1194 & 70 & 59 & 352 & 242 \\
\hline $\mathrm{u}$ & 16 & 15 & 375 & 369 & 1351 & 1421 & 57 & 36 & 399 & 270 \\
\hline
\end{tabular}

Fig. 6 - Número de ocorrências, média e desvio padrão das frequências $(\mathrm{Hz})$ de F1 e F2 das variantes das vogais médias pretônicas

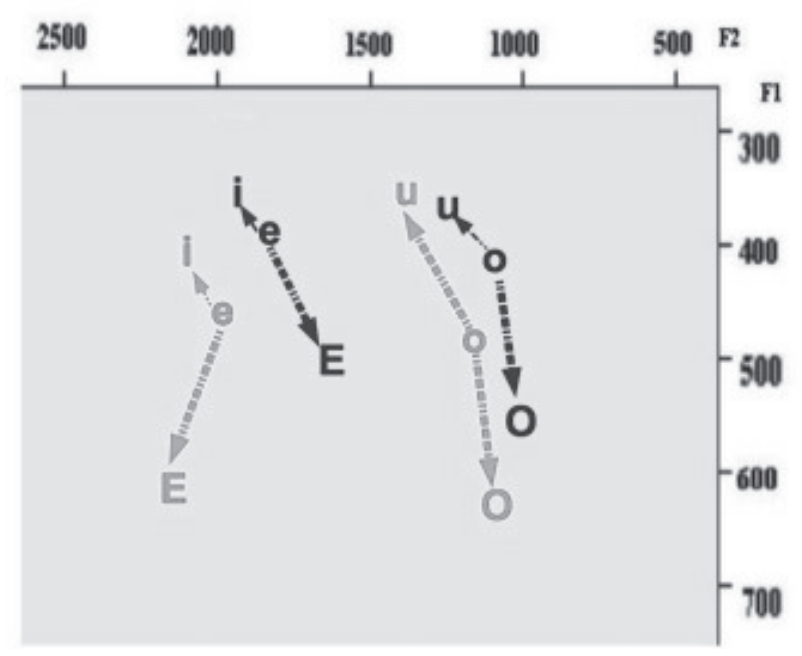

Fig. 7 - Médias de valores de $\mathrm{Hz}$ de F1 e F2 das três variantes das vogais médias pretônicas dos dados de fala feminina (em rosa) e fala masculina (em azul) do corpus de fala lida da variedade de Belém (BE0)

Com o objetivo de tornar mais robustas as análises, futuramente, utilizar-se-á o software Rbrul para o tratamento estatístico dos dados ${ }^{20}$. Outro resultado relevante diz respeito ao número de variantes detectado no corpus da variedade de BE0. As análises dos dados dessa variedade, de caráter ainda preliminar, têm demonstrado que a variedade do português falado na Amazônia paraense possui, no nível acústico, 4 variantes para as vogais médias pretônicas: a) alteamento como em fut[i]bol e c[u]madre; b) manutenção como em fut[e]bol e c[o]madre; c) abaixamento como em

20 Como se tratam de variáveis contínuas, o mais apropriado é proceder a um tratamento estatístico como do tipo do Rbrul. 
fut[E]bol e c[O]madre; d) e há também casos de enfraquecimento das vogais pretônicas ou mesmo de seu total desvozeamento, como em fut [Ø] bol e c $[\varnothing]$ madre. É justamente sobre esta última variante que se discorrerá na seção seguinte.

\section{O Desvozeamento das Vogais Médias Pretônicas: a quarta variante}

O desvozeamento, de forma geral, compreende a perda do traço sonoro ou vozeado de um som, em resultado da sua situação contextual (CRYSTAL, 1988). No que diz respeito ao desvozeamento vocálico,

em geral, são as vogais altas / i / e / u /, que, sendo intrinsecamente curtas e tendo a configuraçWão da cavidade oral de menor tamanho, tendem a perder o vozeamento, o que se manifesta articulatoriamente como uma falta de vibração das pregas vocais e acusticamente como uma ausência de periodicidade no sinal acústico (MENESES, 2012, p. 9).

Como bem assinala Meneses (2012, p. 10), "as vogais desvozeadas apresentam-se psicologicamente na percepção dos falantes nativos", o que justamente se registra nos casos detectados no corpus da variedade linguística de Belém.

Tem-se registro do fenômeno de desvozeamento vocálico em muitas línguas do mundo; no búlgaro (ANDREEVA; KOREMAN, 2008); no francês (CEDERGREN; SIMONEAU 1985; FAGYAL; MOISET, 1999; SMITH, 2003; TORREIRA; ERNESTUS, 2010); no lezguiano (CHITORAN; ISKAROUS, 2008); no grego (DAUER, 1980); no japonês (FUJIMOTO, 2004; HAN, 1962; HIRAYAMA, 2009; HIROSE, 1971; JUN; BECKMAN, 1993; KONDO, 1997; MAEKAWA; KIKUCHI, 2005; SHIRAISHI, 2003; TSUCHIDA, 1997; YOSHIOKA, 1981); no turco (JANNEDY, 1995); no coreano (MO, 2007) e no Zoé (CABRAL; RODRIGUES; CARVALHO, 2010), apenas a título de exemplo. No que diz respeito ao $\mathrm{PB}$, o único trabalho de que se tem conhecimento é o de Meneses (2012).

Durante as etapas de concepção e execução da investigação acústica das vogais átonas do português falado na Amazônia paraense, não se tinha a mínima ideia da existência de tal fenômeno no PB, principalmente envolvendo as pretônicas. Tanto o corpus quanto os demais procedimentos metodológicos não previam o tratamento de vogais desvozeadas. Por essa razão, quando os dados foram "emergindo" no corpus, o primeiro reflexo foi substituí-los por 
dados com a realização plena da vogal, uma vez que as vogais desvozeadas se apresentam com a sua configuração formântica distorcida ou deformada, sua duração totalmente reduzida e registram uma total ausência de F0.

Entretanto, a quantidade de dados de vogais desvozeadas e o fato de quase todos os vocábulos registrarem uma ocorrência ou outra, chamou a atenção e se resolveu, então, verificar mais de perto, e com maior sistematicidade, a razão de tal "deformação". O reflexo inicial foi, portanto, não eliminar esses dados inusitados e inesperados sumariamente do corpus, mas reservá-los para uma exploração futura, o que justamente se faz no presente momento. Optou-se, para o presente trabalho, apenas apresentar de forma qualitativa os casos registrados no corpus analisado do português falado em Belém, uma vez que as análises acústica e fonológica previstas para os mesmos ainda encontram-se em andamento. No total foram registradas 89 ocorrências do fenômeno de desvozeamento no corpus analisado. Dos 74 vocábulos-alvo do corpus, 17 registraram o fenômeno: comadre (1), comer / comendo (2), dezesseis (16), escola (1), escravo / escravidão (17), estante (7), felicidade (1), folia (1), futebol (13), governadores (1), hospital / hospitais (7), menino (2), mosqueteiros (6), pequeno (1), professora (2), segunda (1), teatro (9).

Como pode ser observado, três vocábulos - dezesseis, escravo e futebol - registraram as maiores frequências de ocorrência de desvozeamento da vogal-alvo em todo corpus até o momento. Todas as vogais desvozeadas são percebidas como vogais altas, com exceção da vogal pretônica anterior desvozeada no vocábulo 'professora', que é percebida como média fechada e, de maneira geral, todos os informantes do corpus produziram casos de desvozeamento vocálico, como se constata na figura 8.

\begin{tabular}{|c|c|c|c|c|c|c|c|}
\hline \multicolumn{2}{|c|}{ SEXO } & \multicolumn{3}{c|}{ FAIXA ETÁRIA } & \multicolumn{3}{c|}{ ESCOLARIDADE } \\
\hline Feminino & Masculino & $\begin{array}{c}15 \text { a } 25 \\
\text { anos }^{1}\end{array}$ & $\begin{array}{c}26 \text { a } 45 \\
\text { anos }\end{array}$ & $\begin{array}{c}\text { Acima de 45 } \\
\text { anos }\end{array}$ & Fundamental & Médio & Superior \\
\hline 40 & 49 & 64 & 12 & 13 & 15 & 32 & 42 \\
\hline
\end{tabular}

Fig. 8 - Realização do fenômeno de desvozeamento, considerando o perfil social dos informantes do corpus analisado

Considerando a vogal-objeto, a vogal pretônica anterior registrou uma frequência de ocorrência do fenômeno de desvozeamento superior (72) à vogal posterior (17). Vale observar que ambas ao serem desvozeadas, como já mencionado anteriormente, são percebidas como vogais altas ([ i ] e [ u ]) e ao observar a atuação do contexto precedente na realização do fenômeno, as vogais-alvo tendem a ser desvozeadas quando em sílaba 
com ataque vazio. As consoantes palatais vão favorecer o desvozeamento apenas das vogais anteriores como pode ser observado na figura 9.

\begin{tabular}{|l|c|c|}
\hline & / e / & / o / \\
\hline ONSET VAZIO & 26 & 7 \\
\hline LABIAL & 6 & 4 \\
\hline CORONAL & 2 & 0 \\
\hline PALATAL & 26 & 0 \\
\hline DORSAL & $37^{3}$ & 4 \\
\hline
\end{tabular}

Fig. 9 - Realização do fenômeno por vogal-alvo, considerando o contexto precedente favorecedor

Collischonn; Schwindt (2005), em um trabalho sobre a sequência /SC/ inicial em PB, advogam justamente a favor de uma ausência da vogal no nível subjacente nas sequências iniciais como em 'estudo', 'estrada,' 'escola', 'escravo', estes dois últimos casos também presentes no corpus analisado da variedade português falado em Belém. Com base em evidências de diversas naturezas (morfológicas, fonológicas, fonéticas e lexicais), os autores defendem que o /e/ de 'escada', 'escrever', 'espírito', 'esporte', assim como de 'estudo', 'estrada, 'escola' e 'escravo' é realizado no PB "por um processo de epêntese para dar conta das condições de boa-formação da sílaba em nossa língua" (COLLISCHONN; SCHWINDT, 2005, p.258). Do corpus analisado para o presente trabalho, quatro vocábulos com as mesmas características contextuais dos vocábulos analisados por Collischonn; Schwindt (2005) registraram desvozeamento de vogais pretônicas, a saber: 'escola,' 'escravo,' 'estante' e 'hospital'.

Quando se considera a atuação do contexto seguinte, presente na figura 10, verifica-se que os dados fornecem comprovação empírica para a hipótese de Collischonn; Schwindt (2005), uma vez que todas as vogais desvozeadas, tendo como contexto seguinte preenchido por sibilante, também ocupavam núcleo de sílaba com ataque vazio.

\begin{tabular}{|l|c|c|}
\hline & / e / & / o / \\
\hline ONSET VAZIO & 9 & 0 \\
\hline LABIAL & 11 & 6 \\
\hline CORONAL & 24 & 0 \\
\hline PALATAL & 0 & 1 \\
\hline DORSAL & 2 & 0 \\
\hline SIBILANTE & 26 & 10 \\
\hline
\end{tabular}

Fig. 10 - Realização do fenômeno por vogal- alvo, considerando o contexto seguinte favorecedor 
Ao observar o peso silábico da sílaba-alvo, o mesmo parece não ser relevante para a realização do fenômeno em si, uma vez que se registra uma quase distribuição equânime das ocorrências de vogais desvozeadas, como se constata na figura 11 .

\begin{tabular}{|l|c|c|}
\hline & / e / & / o / \\
\hline LEVE & 46 & 8 \\
\hline PESADA & 26 & 9 \\
\hline
\end{tabular}

Fig. 11 - Realização do fenômeno por vogal-alvo, considerando o peso da sílaba

Ao observar o tipo de vogal tônica do vocábulo, verifica-se que o desvozeamento parece estar mais associado à redução vocálica, uma vez que as vogais tônicas mais favorecedoras não são as vogais altas, mas sim as vogais baixas e a vogal anterior média fechada (Fig. 12). É importante lembrar que as vogais desvozeadas são percebidas como vogais altas. $\mathrm{O}$ último fator interno observado corresponde à distância entre as sílabas-alvo e tônica dos vocábulos. A contiguidade da sílaba tônica também favorece o desvozeamento da vogal-alvo quando a mesma é anterior, como se constata na figura 13 .

\begin{tabular}{|l|c|c|}
\hline VOGAL TÔNICA $^{5}$ & / e / & / o / \\
\hline VOGAL ANTERIOR ALTA $^{\text {I }}$ & 2 & 1 \\
\hline VOGAL POSTERIOR ALTA & 1 & 0 \\
\hline VOGAL ANTERIOR MÉDIA FECHADA & 20 & 5 \\
\hline VOGAL POSTERIOR MÉDIA FECHADA & 2 & 1 \\
\hline VOGAL ANTERIOR MÉDIA ABERTA & 0 & 0 \\
\hline VOGAL POSTERIOR MÉDIA ABERTA & 12 & 2 \\
\hline VOGAL BAIXA & 35 & 8 \\
\hline
\end{tabular}

Fig. 12 - Realização do fenômeno por vogal-alvo, considerando a vogal tônica do vocábulo

Observou-se também a realização do fenômeno com relação ao tipo de coleta de dados. Registrou-se um número maior de desvozeamento nos dados de fala lida (57) em relação aos dados obtidos por indução de imagens ${ }^{21}(34)$. As vogais anteriores foram as vogais que mais registraram casos de desvozeamento tanto nos dados obtidos por teste de imagens (21) quanto nos dados de leitura em voz alta (51). Contrariamente, as vogais posteriores que registraram 11 casos de desvozeamento nos dados induzi-

21 Dados referentes apenas à primeira faixa etária, de 15 a 25 anos.

Organon, Porto Alegre, v. 28, n. 54, p. 115-136, jan./jun. 2013. 
dos por imagens e menos ainda nos dados de leitura (6). Possivelmente, ao concluir o tratamento de todos os dados obtidos com o teste de imagens, registrar-se-á uma frequência de ocorrências bem maior de dados com relação ao protocolo de leitura em voz alta, uma vez que esta situação de leitura parece remeter automaticamente ao contexto escolar.

\begin{tabular}{|c|c|c|}
\hline DISTÂNCIA & $/ \mathrm{e} /$ & $/ \mathrm{o} /$ \\
\hline $1^{6}$ & 55 & 6 \\
\hline 2 & 16 & 10 \\
\hline 3 & 1 & 1 \\
\hline
\end{tabular}

Fig. 13 - Realização do fenômeno considerando a distância entre as sílabas-alvo e tônica do vocábulo por vogal-alvo

No sentido de confirmar mais precisamente a atuação do tipo de protocolo de coleta de dados adotado na realização do fenômeno de desvozeamento vocálico, será feito o tratamento de dados das duas outras faixas etárias obtidos na aplicação do teste de imagens.

\section{Exploração Futura dos Dados}

O próximo passo é proceder a uma análise acústica das vogais desvozeadas, não realizada previamente, com base no trabalho de Meneses (2012), uma possibilidade de exploração adequada dos dados com uma metodologia totalmente coerente para esse tipo de dado.

$\mathrm{O}$ fato de o desvozeamento de vogais ser um fenômeno amplamente estudado em outras línguas naturais, tendo-se o japonês como destaque, é motivo para se proceder a uma descrição completa do fenômeno no corpus do projeto. Outra motivação vem da escassez de estudos sobre o tema no $\mathrm{PB}$, pois até o presente momento, tem-se o conhecimento do trabalho de Meneses (2012), além da presente pesquisa. Entretanto, o objeto desse trabalho é um pouco diferenciado, já que Meneses (2012) estuda as vogais átonas finais, enquanto o nosso centro de interesse compreende as pretônicas. Com relação ao PROBRAVO em si, a presente proposta pretende contribuir diretamente na implementação de uma metodologia adequada para a análise acústica das vogais médias pretônicas de todas as quinze variedades estudadas pela equipe nacional. Portanto, as ações aqui propostas poderão constituir um modelo para ações nacionais mais contundentes e amplas, no que diz respeito ao tema em questão. 
Em outras palavras, a principal meta é a implementação de uma metodologia adequada para a análise acústica das vogais médias pretônicas de todas as quinze variedades estudadas pela equipe nacional do PROBRAVO. O outro trabalho de que se tem conhecimento sobre o assunto, apesar de mais voltado para as características acústicas das vogais tônicas, utilizou dados artificiais e não existentes no sistema português como um todo (ESCUDERO et alli, 2009), portanto, esta proposta prioriza uma análise acústica de dados naturais do português.

\section{Conclusão}

Abordou-se, aqui, um fenômeno raro - o desvozeamento de vogais no PB - no estado da arte do tema do vocalismo átono. Trata-se de mais uma investigação das vogais átonas do $\mathrm{PB}$ conduzida no seio do projeto nacional PROBRAVO. Foi exposto que a realização de vogais desvozeadas, na variedade do português falada em Belém (PA), era um resultado totalmente inesperado no estudo acústico do sistema vocálico do português falado na Amazônia paraense. É interessante observar que mesmo não se tendo formado um corpus específico para investigar o fenômeno aqui abordado e nem mesmo ter-se adotado uma metodologia mais específica para o tratamento desse tipo de fenômeno, foi gratificante constatar que quando se opta por estudar a fala natural nos estudos fonéticos, tem-se a possibilidade de descobrir novas frentes de batalha e, consequentemente, chegar mais próximo de uma descrição fiel do funcionamento da fala. Até o presente momento, 89 ocorrências de vogais pretônicas desvozeadas foram detectadas no corpus formado para o estudo acústico do sistema vocálico do português falado na Amazônia paraense. Ambas as vogais-alvo registraram ocorrência de desvozeamento e três vocábulos, em particular, registraram o maior número de ocorrência do fenômeno: 'dezesseis' (16), 'escravo' (17) e 'futebol' (13).

Apesar de as vogais desvozeadas serem percebidas como vogais altas, com exceção da vogal / e / do vocábulo 'professora', parece não ser o desvozeamento um caso de harmonia vocálica, mas sim de redução vocálica, uma vez que as vogais / a / e / e / são as mais favorecedoras quando ocupam a sílaba tônica. Pretende-se conduzir, assim, uma investigação acústica dos dados, combinada com uma análise fonológica apropriada, uma vez que o desvozeamento ocorrido na pretônica inicial de 'escola', 'escravo' / 'escravidão', 'estante' e 'hospital' pode ser explicado pela hipótese de Collischonn; Schwindt (2005) de não existência de vogal inicial nas sequências /SC/ no nível subjacente.

Organon, Porto Alegre, v. 28, n. 54, p. 115-136, jan./jun. 2013. 


\section{BIBLIOGRAFIA}

ANDREEVA, Brista; KOREMAN, Jacques. The status of vowel devoicing in Bulgarian: phonetic or phonological? In: FORMAL DESCRIPTION OF SLAVIC LANGUAGES: THE FIFTH CONFERENCE (FDSL5), LEIPZIG 2003. Anais... Frankfurt am Main: Peter Lang, 2008, p. 81-91. BISOL, Leda. Harmonia Vocálica: uma regra variável. 1981. Tese (Doutorado em Linguística) - Universidade Federal do Rio de Janeiro, Rio de Janeiro, 1981.

CABRAL, Ana Suelly; RODRIGUES, Aryon; CARVALHO, Fernando. Ensurdecimento Vocálico em Zoé. Revista de Estudos da Linguagem, Belo Horizonte, v. 18, n. 1, p. 51-60. 2010.

CAGLIARI, Luiz Carlos. Elementos de fonética do português brasileiro. 1981. Tese (Livre Docência em Linguística) - IEL, Universidade Estadual de Campinas, Campinas, 1981.

CALDAS, Cristina; FERNANDES, Tabita; CRUZ, Regina. Possibilidade de interferência da Língua Geral Amazônica na combinação de orações em Urubú-Ka’apór. In: WORKSHOP SOBRE LINGUÍSTICA HISTÓRICA E LIINGUAS EM CONTATO: LÍNGUAS INDÍGENAS BRASILEIRAS E DE ÁREAS ADJACENTES. Anais... Brasília: UnB, 2005. (Comunicação Oral). CÂMARA JR., Joaquim Mattoso. Estrutura da Língua Portuguesa. Petrópolis: Vozes, 1969.

CAMPOS, Socorro. Alteamento vocálico em posição pretônica no português falado no Município de Mocajuba, Pará. Dissertação (Mestrado em Letras) - Universidade Federal do Pará, Belém, 2008.

CASSIQUE, Orlando et alii. Variação das vogais médias pré-tônicas no português falado em Breves, Pará. In: HORA, Demerval. (org.). Vogais no ponto mais oriental das Américas. João Pessoa (PB): Ideia, 2009. p. 163-184. CAVALCANTE, Carlos. O sistema vocálico do português falado em Bragança, Pará: análise experimental. Belém: UFPA/ILC/CML. (Projeto de Dissertação de Mestrado), em andamento.

CEDERGREN, Henrietta; SIMONEAU, Louise. La chute des voyelles hautes en français de Montreal: 'As-tu entendu la belle syncope?' In: LEMIEUX, Monique; CEDERGREN, Henrietta (eds.). Les tendances dynamiques du français parlé à Montreal. v.1. Québec: Gouv. du Québec: Office de la langue française / Bibliothèque Nationale du Québec, 1985. p. 57-145. CHITORAN, Ioana; ISKAROUS, Khalil. Acoustic evidence for high vowel devoicing in Lezgi. In: SOCKS et alii (eds). Proceedings of ISSP 8. Strasbourg: [s.n], 2008. p. 93-96. 
COLLISCHONN, Gisela; SCHWINDT, Luiz Carlos. Considerações sobre a sequência /SC/ inicial em Português Brasileiro. Lingua(gem), Macapá, v. 2, n. 2, p. 249-266, 2005.

COSTA, Raquel. Descrição sociolinguística das vogais médias postônicas não-finais /o/ e le/ no português falado no município de Cametá, Pará. 2010. Dissertação (Mestrado em Letras) - Universidade Federal do Pará, Belém, 2010.

CRUZ, Regina. Alteamento vocálico das médias pretônicas no português falado na Amazônia paraense. In: LEE, Seung Hwa. (Org.). Vogais além de Belo Horizonte. Belo Horizonte: Faculdade de Letras da UFMG, 2012a. p. 194-220.

. Vogais na Amazônia paraense. Alfa, São Paulo, v. 3, n. 56, p. 945972, 2012b.

. Projeto de Pesquisa Brazilian Amazon Portuguese vowel system: acoustic analysis (Processo BEX1754/10-6). Brasília: CAPES/Fulbright; New York: New York University. (Relatório técnico-científico aprovado), 2011.

; COSTA, Mara; SILVA, Ana Carolina. Vogais médias pretônicas no português falado em Belém, Pará: análise qualitativa e acústica. In: IV SEMINÁRIO INTERNACIONAL DE FONOLOGIA. Anais... Porto Alegre: UFRGS, Instituto de Letras, 2012. . et alii. As vogais médias pretônicas no português falado nas ilhas de Belém, Pará. In: ARAGÃO, Socorro (org.). Estudos em fonética e fonologia no Brasil. João Pessoa: GT-Fonética e Fonologia / ANPOLL, 2008. CRYSTAL, David. Dicionário de lingüistica e fonética. Rio de Janeiro: Jorge Zahar, 1988.

DAUER, Rebecca. The reduction of unstressed high vowels inmodern Greek, Journal of the International Phonetic Association, n. 10, p. 17-27, 1980. DIAS, Marcelo; CASSIQUE, Orlando; CRUZ, Regina. O alteamento das vogais pré-tônicas no português falado na área rural do município de Breves, Pará: uma abordagem variacionista. [on-line] Disponível em: // www.revel.inf.br/site2007/_pdf/9/artigos/. Arquivo acessado em: 23 de julho de 2012.

ESCUDERO, Paola et alii. A cross-dialect acoustic description of vowels: Brazilian and European Portuguese, Journal of Acoustical Society of America, v. 126, n. 3, p. 1379-1393, set. 2009.

FAGYAL; Zsuzsanna; MOISSET, Christine. Sound change and articulatory release: where and why are high vowels devoiced in Parisian French. In: OHALA, John et alii (eds.). Proceedings of the XIVth International Congress of Phonetic Sciences. Berkeley: University of California, 1999. p. 309-312. 
FREITAS, Simone. As vogais médias pretônicas no falar da cidade de Bragança. 2001. Dissertação (Mestrado em Letras) - Universidade Federal do Pará, Belém, 2001.

FUJIMOTO, Masako. Vowel Duration and Vowel Devoicing in Japanese: a Comparison between Tokyo and Osaka Dialect Speakers, Kokugogaku: studies in the Japanese languages, Tóquio, v. 55, n. 1, p. 2-15, 2004. HAN, Mieko. Unvoicing of vowels in Japanese. Onsei no Kenkyu. (Study of Sounds), Nihon Onsei Gakkai (The Phonetic Society of Japan), Tóquio, n.10, p. 81-100, 1982.

HIRAYAMA, Manami. Postlexical prosodic structure and vowel devoicing in Japanese. 2009. Dissertation (Ph.D. Linguistics ) - Department of Linguistics, Universit of Toronto, Toronto, 2009.

HIROSE, Hau. The activity of the adductor laryngeal muscles in respect to vowel devoicing in japanese. Phonetica, n. 23, p.156-170, 1971.

JANNEDY, Stefanie. Gestural phasing as an explanation for vowel devoicing in Turkish, Ohio State University Working Papers in Linguistics, $\mathrm{n}$. 45, p. 56-84, 1995.

JUN, Sun-Ah; BECKMAN, Mary. A gestural-overlap analysis of vowel devoicing in Japanese and Korean. In: ANNUAL MEETING OF THE LINGUISTIC SOCIETY OF AMERICA. Anais... Los Angeles, jan. 1993. KONDO, Mariko. Mechanisms of Vowel Devoicing in Japanese. Edinburg. Ph.D. (Dissertation in Linguistics) - University of Edinburg, Edinburg, 1977.

MAEKAWA, Koichi; KIKUCHI, Hideaki. Corpus-based analysis of vowel devoicing in spontaneous japanese: an interim report. In: VAN DE WEIJER, Jeroen; NANJO, Kensuke;

MENESES, Francisco. Investigação acústico-articulatória das vogais desvozeadas no português brasileiro. 2012. Dissertação (Mestrado em Linguística) - Instituto de Estudos da Linguagem, Universidade Estadual de Campinas, Campinas, 2012.

MO, Yoonsook. Temporal, spectral evidence of devoiced vowels in Korean. In: PROCEEDINGS OF ICPHS. Anais... Saarbrucken, 2007. MORAES, João; CALLOU, Dinah; LEITE, Yonne. O sistema vocálico do português do Brasil: caracterização acústica. 2. ed. In: KATO, Mary (org.). Gramática do Português Falado. Campinas: Editora da Unicamp, 2002. p. 33-51.

NINA, Terezinha. Aspectos da variação fonético-fonológica na fala de Belém. 1991. Tese (Doutorado em Língua Portuguesa) - Faculdade de Letras, Universidade Federal do Rio de Janeiro, Rio de Janeiro, 1991. 
NISHIHARA, Tetsuo (eds.). Voicing in Japanese. Berlin; New York: Mouton de Gruyter. 2005. p. 205-228.

OLIVEIRA, Miguel. A comparative study between Brazilian Portuguese anda American English intrisic pitch of vowels, NWLC14, p. 146-155, 1999. RIBEIRO, Darinka. Alçamento de vogais postônicas não finais no português de Belo Horizonte - Minas Gerais: uma abordagem difusionista. 2007. Dissertação (Mestrado em Língua Portuguesa e Linguística) - Faculdade de Letras, Universidade Federal de Minas Gerias, Belo Horizonte, 2007.

RODRIGUES, Aryon. As línguas gerais sulamericanas. Papia, n. 4,v. 2, p.6-18, 1996.

RODRIGUES, Doriedson. Da zona urbana à rural/entre a tônica e a pretônica: alteamento /o/ > [u] no português falado no município de Cametál NE paraense: uma abordagem variacionista. 2005. Dissertação (Mestrado em Letras) - Universidade Federal do Pará, Belém, 2005.

RODRIGUES, Doriedson; ARAÚJO, Marivana. As vogais médias pretônicas / e / e / o / no português falado no município de Cametá, Pará - a harmonização vocálica numa abordagem variacionista. Cadernos de Pesquisa em Linguística: Variação no Português Brasileiro, v. 3, Porto Alegre, p. 104-126, nov. 2007.

RODRIGUES, Doriedson; REIS, Giussiany. Variação da nasalização vocálica pretônica seguida de consoante nasal na sílaba seguinte no português falado no município de Cametá, Pará. In: LEE, Seung H (Org.). Vogais além de Belo Horizonte. Belo Horizonte: UFMG, 2012. p. 322-348. SHIRAISHI, Hideaki. Vowel devoicing of Ainu: How it differs and not differs from vowel devoicing of Japanese. In: HONMA, T.; OKAZAKI, M.; TABATA, T; TANAKA, S. A. New Century of Phonology and Phonological Theory. Tokyo: [s.n], 2003. p. 237-249.

SILVA, Myriam Barbosa. As pretônicas no falar baiano: a variedade culta de Salvador. 1989. Tese (Doutorado em Língua Portuguesa) - Faculdade de Letras, Universidade Federal do Rio de Janeiro, Rio de Janeiro, 1989. SILVA NETO, Serafim. Introdução ao estudo da Língua Portuguesa no Brasil. 4. ed. Rio de Janeiro: Presença, 1957. SMITH, Caroline. Vowel devoicing in contempory French. Journal of French Languages Studies, n. 13, v. 2, p. 177-194, 2003.

SOUSA, Josivane. A variação das vogais médias pretônicas no português falado na área urbana do município de Belém, Pará. 2010. Dissertação (Mestrado em Letras) - Universidade Federal do Pará, Belém, 2010. TORREIRA, Francisco; ERNESTUS, Mirjam. Phrase-medial vowel devoicing in spontaneous French. Interspeech 2010, Chiba, p. 26-30, sep. 2010. 
TSUCHIDA, Ayako. Phonetics dans Phonology of Japanese Vowel Devoicing. 1997. Dissertation (PhD. Linguistics) - Cornell University, Ithaca, NY, 1997.

YOSHIOKA, Hiroshi. Laryngeal adjustments in the production of the fricative consonants and devoiced vowels in Japanese. Phonetica, n. 38, p. 236-251, 1981.

Recebido em: 29/03/2013; Aceito em: 16/06/2013

\section{Notas}

1 Os dados dessa faixa etária já foram todos tratados, o que justifica um número de ocorrências mais elevado em relação às demais faixas etárias.

2 Todos casos de africada alveopalatal.

3 Apenas casos de consoantes africadas.

4 Quando o segmento seguinte encontra-se na mesma sílaba, ou seja, na posição de coda, optou-se por utilizar os traços sibilante e rótico para classificá-lo.

5 Não se considera a posição do véu palatino.

6 Vogal pretônica contígua à sílaba tônica. 